Article

\title{
An Expansion Planning Method for Extending Distributed Energy System Lifespan with ESS
}

\author{
Said Mirza TERCAN ${ }^{1}$, Onur ELMA ${ }^{1}$, Erdin GÖKALP 1, Umit Cali ${ }^{2}$ \\ 1 Faculty of Electric Electronics, Department of Electrical Engineering, Yildiz Technical University, Istanbul, \\ Turkey, stercan@yildiz.edu.tr, onurelma@yildiz.edu.tr, gokalp@yildiz.edu.tr \\ 2 Department of Electric Power Engineering, Norwegian University of Science and Technology, Trondheim, \\ Norway, umit.cali@ntnu.no \\ * Correspondence: umit.cali@ntnu.no
}

\begin{abstract}
Growing energy demand in the distributed energy system (DES) besides new charging loads of electric vehicles (EVs) make DES infrastructure unavailable earlier than normal projections. DES lines need to be upgraded to carry the modern demand of customers. DES line upgrade (LU) cost minimized and deferred to the next years by using energy storage system (ESS). ESS offers the opportunity to use energy flexibly in the distribution grid. It is possible to use ESS to shift the inevitable upgrade costs of the distribution grid elements and increase the power quality of the distribution grid. In this study, a method is proposed to extend the lifespan of DES with ESS and reduce line upgrade and investment costs in the distribution system. For this purpose, the IEEE 33 bus test grid is used, and the proposed method is tested and analyzed with different case studies. According to the results, the proposed method can reduce the investment cost by up to $80 \%$. Besides, ESS usage considering load increase and line conditions of the distribution grid, upgrade costs of distribution grid are shifted, resulting in an optimal dimensioning and positioning while extending the lifespan of the distribution grid elements and, at the same time, offering significant improvements in energy quality. Additionally, it is seen that the power losses of the distribution grid are reduced up to $26 \%$, and the voltage profile of buses is improved with the usage of ESS.
\end{abstract}

Keywords: Energy storage systems, distribution energy systems, cost analysis, upgrade deferring, voltage improvement.

\section{Introduction}

\subsection{Motivation and Background}

Distributed energy systems (DES) have increasing loads due to not only annual demand growth but also the rapid new charging demand of electric vehicles in the next years. The load growth factor has been assumed constant. In the next few years, the increase in the number of electric vehicles (EVs) will make unreal this constant load growth factor, and the unavailability of DES will be nonexpectable. It is not easy to determine EV penetration, but it is obvious that EV penetration brings more loads on the DES infrastructure. However, many developed local governments have already decided to prohibit internal combustion engine vehicles inside their cities. For example, California will not allow gasoline-powered vehicles to be sold inner the state since 2035. Thus, the penetration of EVs rapidly overloads DES earlier. Overloading due to new loads is a short term event lasting about 1-4 hour a day [1]. However, it causes permanent damages to DES. Overloading causes not only more power loss and voltage drop but also short or long energy outages. Expansion planning is crucial for the distribution system operator (DSO) and customers. Some methods of expansion planning consist of adding distributed generation, load shedding, and line upgrading, and installing centralized or distributed ESS. Energy storage system (ESS) is a short-term and long-term solution to control overloading, among other methods. Line upgrade (LU) cost of expansion planning of DES can be deferred by the utilization of commercially existing ESS technologies. Stored energy in ESS 
can be discharged to DES during especially peak time to keep the DES capable of meeting the ongoing demand. Short- or long-term, expensive investment of LU for DES and amount of energy not supplied to customers due to overloading resulting damages on DES can be prevented or decreased thanks to ESS. Although ESS can prevent overloading on DES, installation and operation costs of ESS should be reduced by utilization of ESS for some auxiliary applications. For example, energy can be exchanged to profit. That energy bought at a low price by storing to ESS and sold at a high price by discharging to DES, decreases total cost thanks to hourly varying electricity price in the energy market. This profit is called arbitrage revenue, which is naturally related to the usage of ESS. Another auxiliary profit of using ESS is decreasing the occupation cost of transmission lines. This cost is correlated; the power comes from the transmission line to DES at a certain time interval.

DES is kept capable by using ESS to meet peak demand without overloading. ESS exchanges energy between peak and off-peak time. To reduce the peak load of DES, ESS stores energy from the grid when load demand is low and discharges to DES when load demand is high [1-4]. The DES infrastructure meets growing load demand by decreasing the current in the lines since as the power getting from the grid decreases. ESS is suitable for expansion planning besides many applications. For instance, energy outages can be prevented by using ESS in DES [5]. Studies in the literature about the usage of ESS in DES are briefly described in the next part.

\subsection{Literature review}

Expansion planning of DES with ESS can reduce or shift the upgrade costs of DES, such as distribution lines and transformers. In one study, ESS installation and operation costs and arbitrage revenues, and the costs of transmission line usage and upgrade of DES were mathematically modeled and resulted that DES with ESS can be offered to DSO to reduce upgrade cost [6]. In [7], the economics of ESS technologies performance is examined at the distribution substation transformer rated 30 MVA. It was stated that polysulfide bromide batteries would be more cost-effective than vanadium redox batteries. A feasibility condition was defined for ESS installation according to the net present values (NPV) of the projects. In 2006, it was investigated that distributed generation (DG) on deferring DES upgrade such as line or transformer [8]. Without ESS, a concern appears that the production of renewable energy sources (RES) will be less than expected, especially during peak times if overload control is made using only DG allocation. It is also stated that DG helps to reduce electricity bills. Making a profit by using ESS in DES can be described by deferral of LU cost as a function of load increase, penetration level of DG, and peak shave rate [9]. In addition, this shows that the financial feasibility of using ESS in DES for deferring upgrade increases with increases in either the rate of load increase or PV penetration levels. As a result, in the future, load growth factor and expected level of PV penetration must be carefully considered to determine the financial viability of ESS in DES to defer the upgrade cost. The planning of DES with ESS continues to become widespread. A linear programming-based algorithm is introduced to allow DES to be reconfigured with optimum power flow and minimum power losses provided by DG [10]. For an optimal configuration, DG has been shown to reduce losses and current in lines and improve the overall voltage profile. It is essential to know the amount of demand and availability of DG, as it will vary according to changes in the load and output of DG in real-time operation. A new distribution grid planning is proposed that can determine the location and size of ESS, which minimizes total grid upgrade cost by genetic algorithm and dynamic programming [11]. The cost of ESS includes capital investment and operating costs. Multipurpose optimization approach combined by DG and grid reconfiguration reduces the cost of LU and DG units (capital, O\&M costs) and minimizes energy losses and total gas emissions [12]. In [13], when DES was reconfigured, with the help of ESS, adding new connection switches between some lines prevented the customers connected to the fault lines from being non-energized. However, installing connection lines with switches may be expensive because underline cable installation needs an available ground position while overhead lines are not allowed inner the cities. It was proposed by [14] that a method find out the optimum reconfiguration of DES and location of RES with optimally sized considering the suspicions of load, price, and output power of RES. 
As a general principle, ESS charges when the unit price of energy is low during the day. The discharging time of the stored energy is the period in which the unit price is high. In this way, a certain amount of revenue is generated due to the charging-discharging of energy. That is called arbitrage profits. Likewise, some profits may come from the usage of ESS in DES. In order to make a profit by using ESS, sizing and placement of it is crucial. Many studies have been conducted in the literature, such as where and to what extent ESS will be placed in DES. Some of them made an economic analysis by taking into account multiple parameters [4,15-19]. The main parameters are arbitrage revenues and power losses. In [6], ESS was connected to DES, while energy arbitrage was achieved, the cost of using the transmission system was reduced, and the necessary cost of the upgrade was deferred. Arbitrage profits were also calculated in the proposed method, which includes the upgrade deferral of DES elements to determine the size and location of ESS, which was determined by the genetic algorithm [20,21]. Improving bus voltages is another benefit of using ESS in DES. In [22], an inverter-based ESS strategy has been developed to improve bus voltage using minimum energy from ESS. In order to regulate bus voltages, a control strategy is proposed to provide active and reactive power to the system. The proposed technique was evaluated by simulation on a three-phase DES with varying loads over time. It showed that ESS improves the voltage profile on all lines and reduces ENS (energy not supplied) significantly [23]. Via expansion planning of DES can prevent bus voltages of DES from going outside of the margins while reducing the overloading of lines. Renewable energy sources (RES) are increasingly connected to the DES in recent years due to their environmentally friendly generation. Due to their intermittency nature, it is envisaged to connect RES to the grid together with an ESS. The use of ESS to prevent reverse power flow and maximize distributed RES integration into DESs was examined [24]. In [25], it was shown that economically feasible integrating ESS with DES is if and only if cheaper ESS types were used. For detailed information on using ESS when integrating RES into DES, refer to references [25-29].

\subsection{Content and Contribution}

In this study, ESS usage to defer upgrade investments in DES using a cost minimization-oriented approach is proposed. There are seminal studies that focus on ESS application in the distribution grid. However, these do not contribute to the use of ESS for investment postponement. Among them, even many studies dealings with ESS usage are about integration of RES, few of them have referred to deferring of distribution grid upgrade. In [6], where the integration of ESS into the distribution grid considers the postponing of the upgrade cost of the lines, this postpone is not applied to a real distribution grid. There is no detailed information about which lines or when they are renewed in $[20,21,30]$. The original contribution of this study is to determine the lines to be renewed individually, considering load flow analysis (LFA) calculated each year with load growth in a real distribution grid model. DES model is implemented in PSS Sincal software [31], where LFA and load profile results can be analyzed more easily and clearly. The original contributions of this study are:

- A new method has been proposed to extend the lifespan of DES with ESS deferring upgrade investments of DES infrastructure.

- The effect of ESS size and position on investment of ESS and DES upgrade rollover is examined.

- The proposed method prevents DES from voltage violation and reduces the energy costs of DES.

- Simulations of ESS integration are performed based on real distribution grid data, which is the IEEE 33 bus model.

- The proposed method has been tested with different case studies, including centralized and decentralized ESS.

- The economic feasibility of ESS for different battery types has been examined.

\subsection{Organization of the paper}

The remainder of the study is organized as follows: In the second part, the methodology of expansion planning of DES with ESS is introduced with mathematical equations. In the third part, the modeling of DES and ESS is widely described. In the fourth part, the case studies are given. In the 
fifth part, the technical analysis results are provided in detail, and the feasibility of expansion planning of DES with ESS is discussed. The last part includes the concluding remarks.

\section{Methodology}

Expansion planning of DES with ESS decreases the number of upgraded lines and defers the cost of upgrade investment of DES lines. The methodology of expansion planning of DES with ESS is described in Fig. 1. Increasing load in number and size besides integrating EV fast and slow charging loads causes unavailability of DES infrastructure. Instead of upgrading lines since exceeding thermal limit after certain years, installing ESS into DES can reduce upgraded lines and extend the lifespan of DES. Exceeding thermal limit of lines in DES is determined by peak loading conditions. In other words, any component of DES such as line, transformer, etc. has the current above the nominal ampacity of the line is to be upgraded in the expansion planning. Thus, it is sufficient that LFA is run for only peak conditions to determine expansion planning of DES. Line upgrades decision are based on the extreme power flow especially as peak load state [20]. If peak loading can be decreased by using ESS, lines keep serving to DSO and customers. LFA should be repeated every planning stages considering the annual load growth factor. First, determining unavailability of lines by LFA with annual load growth for each stages without ESS is done, and then the result is used to compare the deferring upgrade after ESS use. The LU cost of each upgraded lines are calculated and normalized to the beginning of planning stage. Second, after installing ESS to certain locations of DES, again unavailability of lines for each case are determined. In every case, LFA is repeated as the number of planning years. Third, expansion planning of DES with ESS is analyzed by centralized and decentralized use of ESS. Calculations are made the following equations.

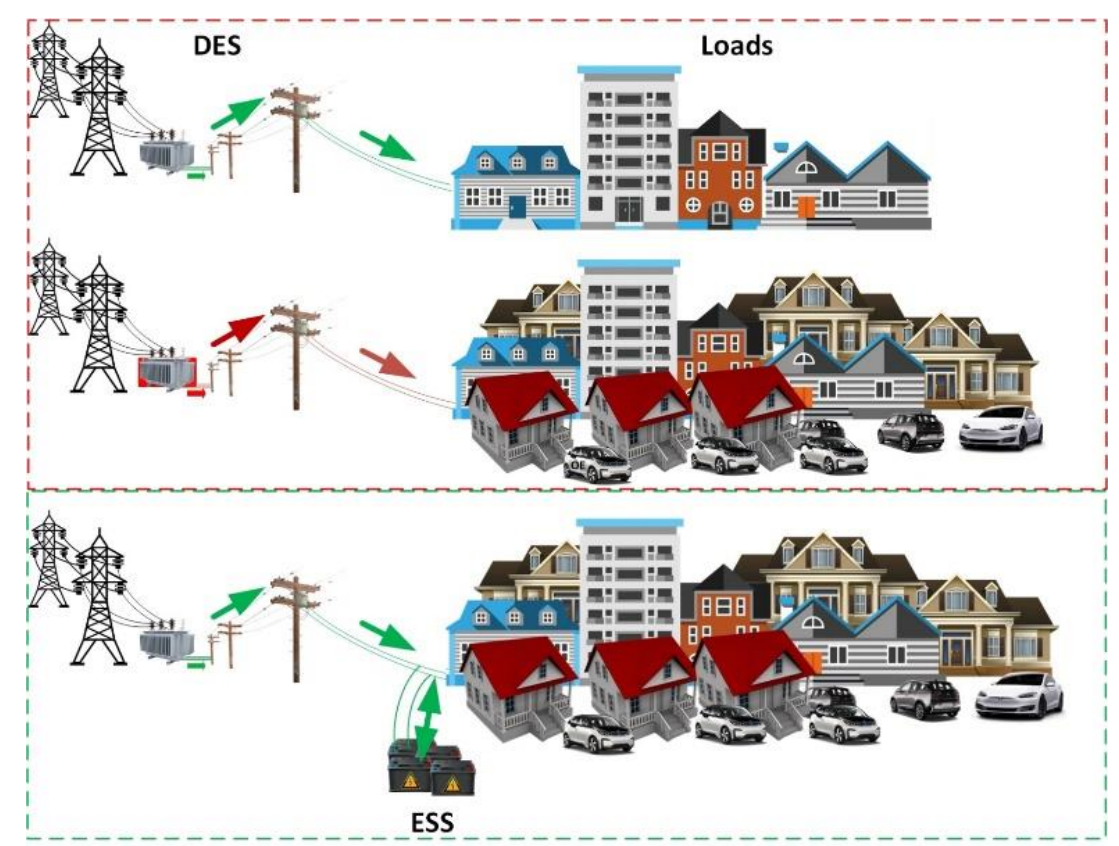

Figure 1. A general overview of expansion planning in DES with ESS

The determining of unavailability of line $i$ is described by a constraint in Eq. (1).

$$
I_{i} \leq I_{i}^{\max }
$$

The thermal current limit of line $i$ is $I_{i}^{\max }$ in ampere. The power loss of line $i$ is described by Eq. (2). 


$$
P_{\text {loss }}=\sum_{i=1}^{M} I_{i}^{2} \cdot r_{i} \cdot l_{i}
$$

The total power loss of $M$ lines in DES is calculated by using resistance $\left(r_{i}\right)$ and length of the line $\left(l_{i}\right)$.

LU cost $\left(C_{\text {upgrade }}\right)$ consists of line investment cost $\left(C_{\text {line }}\right)$ and line operating \& maintenance cost $\left(C_{O M}\right)$. Total LU cost of $M$ lines related to their length $\left(L_{m}\right)$ and transmitting power on the line $\left(P_{m}\right)$. The LU cost is given in Eq. (3). In the other words, the LU cost is the investment of uninstalling old lines and installing a new one. The cost of the line install relates to the length of a new line. Costing of line operation consists of operation and maintenance costs together related to the power carrying through the line. In eq. (3), the summation of cost of any new lines that have the same length of the overloaded lines, the summation of cost of operation of the new lines according to new growing demand.

$$
C_{\text {upgrade }}=\sum_{m=1}^{M} L_{m} \cdot C_{\text {line }}+P_{m} \cdot C_{\text {line }} \text { OM }
$$

For $E_{b}^{E S S}$ is ESS size in $\mathrm{kWh}$ of $b^{\text {th }}$ ESS, total ESS investment cost for $B$ number of ESS is given in Eq. (4).

$$
C_{E S S}=\sum_{b=1}^{B} E_{b}^{E S S} \cdot\left(C_{E S S}+C_{E S S_{O M}} \cdot L\right)
$$

$C_{E S S}$ is battery investment cost, $C_{E S S_{O M}}$ is battery O\&M cost, $L$ is battery life in a year. All ESSs were installed the beginning of the operation time that lasts 20 year. Therefore, L equals to 20 in this paper.

For calculation of net present values of investment and upgrade costs, the following equations (5)-(7) were used.

$$
P=A \cdot\left[\frac{(1+i)^{L}-1}{i \cdot(1+i)^{L}}\right]
$$

where $P$ is the present value of $A$, which is a fixed value of cost for $L$ year.

$$
F=C \cdot\left[\frac{i \cdot(1+i)^{(p+v)}}{(1+i)^{v}-1}\right]
$$

where $F$ is the total amount of interest to be paid, $C$ is cost, $i$ is the interest, $p$ is a year to be paid, and $v$ is the term of credit.

$$
F V=P V \cdot(1+i)^{k}
$$

where $F V$ is the future value, $P V$ is the present value, and $k$ is the year that payments are shifted to a later year.

The LU cost of DES is calculated using Eqs. (1) - (7) and deferring LU cost to a later year with ESS in DES is described as follows, given in Figure 2. 


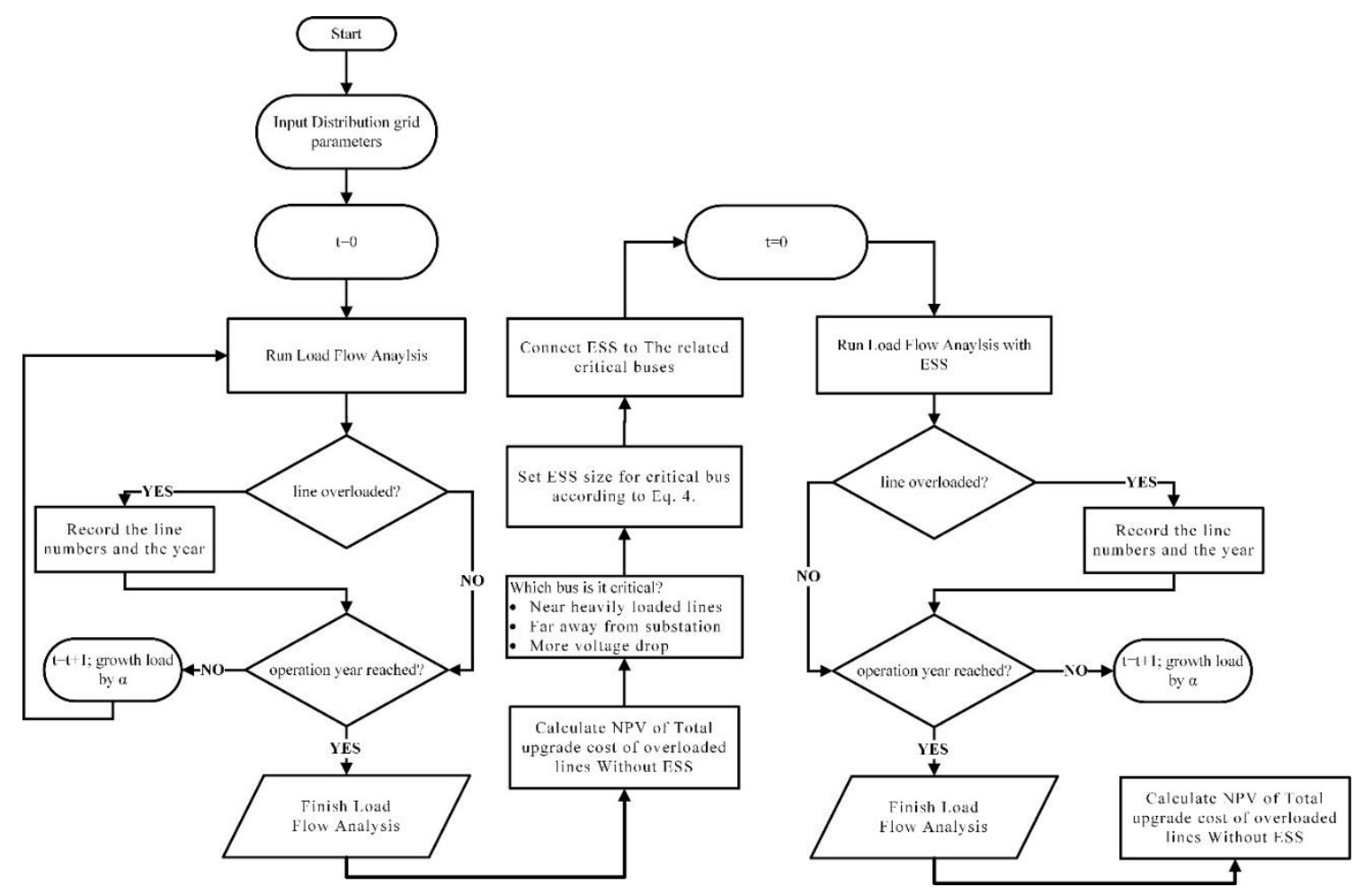

Figure 2. Flowchart of the economic calculation of the upgrade postpone using ESS in DES

Distribution grid parameters such as line and load data are entered, and LFA is run for stage, $\mathrm{t}=0$ without ESS. In the result of the first LFA, any line has a load above the thermal limit is recorded in the expansion planning stage. Then $t$ is increased by 1 , and loads are increased by load growth factor $\alpha$. LFA is repeated until to the planning stage year, $t=L$. In the results of all following LFA, the NPV of LU costs of all recorded line in the expansion planning are calculated at the end of planning stages. This calculation includes only investments of LU, not any ESS.

Candidate buses that ESS connected to are identified as the following features: 1-Near heavily loaded lines, 2-Far away from substation, 3-More voltage drop. Before starting LFA with ESS, ESS is connected to each candidate bus for each case . LFA is run for stage, $t=0$ with ESS. In the result of the first LFA with ESS, any line has a load above the thermal limit is recorded in the expansion planning stage. Then $t$ is increased by 1 , and loads are increased by load growth factor $\alpha$. LFA with ESS is repeated until to the planning stage year, $\mathrm{t}=\mathrm{L}$. In the results of all following LFA with ESS, the NPV of LU costs of all recorded line in the expansion planning and ESS investment costs are calculated at the end of planning stages. This calculation includes both investments of LU and ESS.

\section{System Modeling}

Modeling of DES with ESS includes distribution lines, loads, and ESS units. First, the modeling of the distribution grid is described, and then the modeling of ESS is explained to the reader.

\subsection{Modeling of Distribution Grid}

In this study, IEEE 33 bus model is used to analyze ESS evaluation with different sizes and locations in DES. IEEE 33 bus grid model is used because it has several branches and a radial network structure similar to current DES. IEEE 33 bus model has a totally 3.7 MW real power, and 2.3 MVAr reactive power is given in Figure 3. The power is suitable for DES analyses since similar to the load level of distribution grid. This model has 33 buses and 32 lines and one distribution transformer connected to the distribution substation [32]. Bus numbers are shown in the figure above black dots, and line numbers are shown below lines with tags starting by the letter "L," e.g., "L28". Information about the model is given in Table 1. 


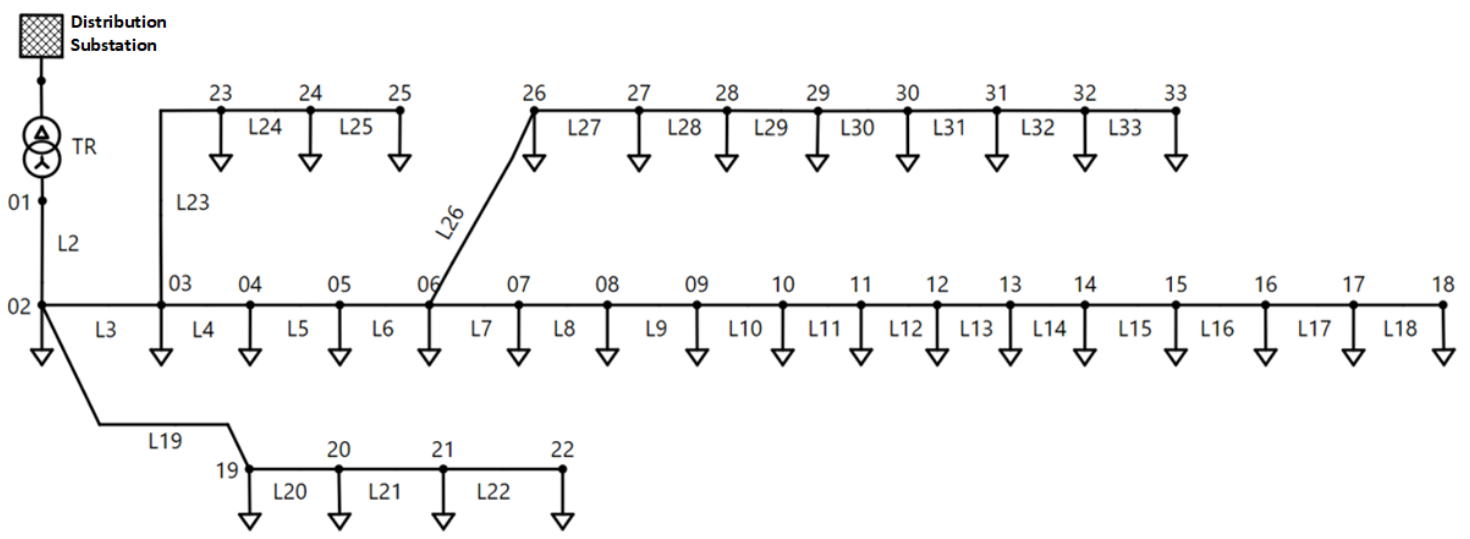

Figure 3. Single-line of the model of DES

For clear evaluation of expansion planning of DES with ESS, distribution lines in the model are divided into two categories, the first main lines that have severely loaded, minor lines, which have a smaller amount loaded. Main and minor lines are assumed to have conductors as pigeon and swallow; they have $275 \mathrm{~A}$ and 120 A current-carrying limits, respectively. These limits are used as a reference to illustrate comparatively overloading of lines and LU investments. Namely, L2, L3, L4, L5, and L6 are assumed as main lines and as pigeon, which has $275 \mathrm{~A}$ thermal current limit since they have more loads than others; the other lines have $120 \mathrm{~A}$ thermal current limit. If a line has a current more than these limits, the line is assumed as overloaded. According to values related, line lengths are calculated that pigeon has $0.3366 \Omega / \mathrm{km}$ resistance while swallow has $1.0742 \Omega / \mathrm{km}$ resistance. Line lengths are also given in Table 1.

Table 1. Information about loads and lines in DES

\begin{tabular}{ccccccc}
\hline \# of Line & $\mathbf{R}[\Omega]$ & $\mathbf{X}[\Omega]$ & Length $[\mathbf{k m}]$ & Thermal Limit [A] & Load [kW] & Load [kVar] \\
\hline L2 & 0.0922 & 0.0477 & 0.27 & 275 & 100 & 60 \\
\hline L3 & 0.4930 & 0.2511 & 1.46 & 275 & 90 & 40 \\
\hline L4 & 0.3660 & 0.1864 & 1.09 & 275 & 120 & 80 \\
\hline L5 & 0.3811 & 0.1941 & 1.13 & 275 & 60 & 30 \\
\hline L6 & 0.8190 & 0.7070 & 2.43 & 275 & 60 & 20 \\
\hline L7 & 0.1872 & 0.6188 & 0.17 & 120 & 200 & 100 \\
\hline L8 & 1.7114 & 1.2351 & 1.59 & 120 & 200 & 100 \\
\hline L9 & 1.0300 & 0.7400 & 0.96 & 120 & 60 & 20 \\
\hline L10 & 1.0400 & 0.7400 & 0.97 & 120 & 60 & 20 \\
\hline L11 & 0.1966 & 0.0650 & 0.18 & 120 & 45 & 30 \\
\hline L12 & 0.3744 & 0.1238 & 0.35 & 120 & 60 & 35 \\
\hline L13 & 1.4680 & 1.1550 & 1.37 & 120 & 60 & 35 \\
\hline L14 & 0.5416 & 0.7129 & 0.50 & 120 & 120 & 80 \\
\hline L15 & 0.5910 & 0.5260 & 0.55 & 120 & 60 & 10 \\
\hline L16 & 0.7463 & 0.5450 & 0.69 & 120 & 60 & 20 \\
\hline L17 & 1.2890 & 1.7210 & 1.20 & 120 & 60 & 20 \\
\hline L18 & 0.7320 & 0.5740 & 0.68 & 120 & 90 & 40 \\
\hline L19 & 0.1640 & 0.1565 & 0.15 & 120 & 90 & 40 \\
\hline L20 & 1.5042 & 1.3554 & 1.40 & 120 & 90 & 40 \\
\hline
\end{tabular}




\begin{tabular}{|c|c|c|c|c|c|c|}
\hline L21 & 0.4095 & 0.4784 & 0.38 & 120 & 90 & 40 \\
\hline L22 & 0.7089 & 0.9373 & 0.66 & 120 & 90 & 40 \\
\hline L23 & 0.4512 & 0.3083 & 0.42 & 120 & 90 & 50 \\
\hline L24 & 0.8980 & 0.7091 & 0.84 & 120 & 420 & 200 \\
\hline L25 & 0.8960 & 0.7011 & 0.83 & 120 & 420 & 200 \\
\hline L26 & 0.2030 & 0.1034 & 0.19 & 120 & 60 & 25 \\
\hline L27 & 0.2842 & 0.1447 & 0.26 & 120 & 60 & 25 \\
\hline L28 & 1.0590 & 0.9337 & 0.99 & 120 & 60 & 20 \\
\hline L29 & 0.8042 & 0.7006 & 0.75 & 120 & 120 & 70 \\
\hline L30 & 0.5075 & 0.2585 & 0.47 & 120 & 200 & 600 \\
\hline L31 & 0.9744 & 0.9630 & 0.91 & 120 & 150 & 70 \\
\hline L32 & 0.3105 & 0.3619 & 0.29 & 120 & 210 & 100 \\
\hline L33 & 0.3410 & 0.5302 & 0.32 & 120 & 60 & 40 \\
\hline
\end{tabular}

According to Table 1, the longest line is L6, which has $2.43 \mathrm{~km}$ in length. L19 is the shortest line as the length is only $170 \mathrm{~m}$. Loads in table 1 show loads connected to the related bus. The largest two loads, which are $420 \mathrm{~kW}$ and $200 \mathrm{kVAr}$, are connected to bus 24 and 25 . The most loaded line is L2 at the beginning of the DES model.

\subsection{Modeling of ESS}

The recent developments are offering new possibilities, including grid support in different manners such as load shifting [33,34], power quality [35], smoothing power generation of RES [36], and power loss reduction [37,38]. The common commercial ESS types of ESS used in the expansion planning of DES in this paper are lead-acid, lithium-ion, vanadium redox, and compressed air [36]. Some parameters about these types of ESS are given in table 2. There are many ESS types, but considering increasing attraction on EVs in the near future, EV batteries' second use will be more available cheaply and in number. After 5-8 years of service in EV, the batteries are insufficient for the power and energy need of EV [39].

The state of energy (SoE) of ESS is given in Eq. (8). SoE is kept between $20-80 \%$ for all ESS units in the DES model because of avoiding more age effects, given in Eq. (9) [40].

$$
\begin{gathered}
\operatorname{SoE}_{b}(t)=\operatorname{SoE}_{b}(t-1)+\int \frac{P_{b}^{E S S}(t) \cdot d(t)}{E_{b}^{E S S}} \\
\operatorname{SoE}_{\text {min }} \leq \operatorname{SoE}_{b} \leq S o E_{\text {max }}, \forall b \in B \\
V_{n}^{\text {min }}<V_{n}(t)<V_{n}^{\text {max }}, \forall n \in N
\end{gathered}
$$

In this study, charging of ESS is controlled by Sincal when the voltage of the bus that ESS connected to is above the limit $\left(V_{n}^{\max }\right)$, charging starts, and if the voltage of the bus is below the limit $\left(V_{n}^{\text {min }}\right)$ ESS starts to discharge. The voltage of each bus in DES has to keep in the voltage limit given in Eq. (10). 
Table 2. Parameters about different types of ESS

\begin{tabular}{ccccccc}
\hline Technologies & $\begin{array}{c}\text { Efficiency } \\
\mathbf{( \% )}\end{array}$ & $\begin{array}{c}\text { Energy } \\
\mathbf{d e n s i t y} \\
{[\mathbf{W h} / \mathbf{K g}]}\end{array}$ & $\begin{array}{c}\text { Life } \\
(\text { years) }\end{array}$ & $\begin{array}{c}\text { Ecological } \\
\text { Effect }\end{array}$ & $\begin{array}{c}\text { Installation } \\
{[\mathbf{\$} / \mathbf{k W h}]}\end{array}$ & $\begin{array}{c}\text { Operation } \\
\mathbf{[ \$ / k W h ]}\end{array}$ \\
\hline $\begin{array}{c}\text { Lead } \\
\text { acid (LA) }\end{array}$ & $85-90$ & $30-50$ & $5-15$ & High & 250 & 20 \\
\hline Li-ion & $90-100$ & $75-200$ & $5-15$ & Moderate & 350 & 20 \\
\hline $\begin{array}{c}\text { Vanadium } \\
\text { Redox (VR) }\end{array}$ & 85 & $60-85$ & $5-10$ & High & 740 & 20 \\
\hline $\begin{array}{c}\text { Compressed } \\
\text { Air (CA) }\end{array}$ & $70-90$ & $2-6$ & $20-40$ & Moderate & 1250 & 28 \\
\hline
\end{tabular}

Lead-acid batteries are known as very common and widely used as chemical energy storage. Installation and operational costs are very competitive, among other types of ESS. Lithium-ion batteries are preferable ESS option for grid applications with the increasing popularity of EVs having massive sized li-ion batteries. Long life cycle and low operational cost make li-ion a new challenging type of storage. Comprehensive performance and grid-scale applications of Vanadium redox batteries make VRB as good ESS prospects in DES application, although expensive investment costs [41]. Compressed air ESS investment cost is much higher than other ESS types, while its life expectancy is longer than different battery types [42]. Thus, the utilization of compressed air ESS in DES has certain benefits; hence, it is investigated in this paper. Information about the installation and operational costs of different types of ESS are given in Table 2.

\section{Case Studies}

Case studies were designed to include centralized and distributed ESS. LFA is used to show the loading of DES lines exceeding limit for all cases, and LU cost for all recorded lines of DES is calculated through expansion planning stage which is 20 years. Every year in LFA simulation, all loads were increased by $\alpha$. In LFA, the load growth factor $\alpha$ was 3\% annually. In the first case, LFA was run without ESS. Thus, case 1 is the base case used for comparison. According to the flowchart, candidate buses are bus number N09, N17, N26, and N29. In case 2, ESS was connected to the bus N17, which is more loaded and far from the substation and has the most voltage drop. In cases 3, 4, and 5, ESS with the same size in case 2 connected to bus number N09, N29, and N26, respectively. Cases 2-5 have a centralized energy storage unit. Thus, there is only one ESS with the same size connected to different candidate buses. Cases 6 and 7 have decentralized energy storage units. In case 6, ESS with the same in total size but half-size two units were connected to two different buses N29 and N17. In case 7, to show the difference of ESS size on DES, the size of ESS connected to N17 was increased by $100 \mathrm{kWh}$. Namely, the $300 \mathrm{kWh}$ ESS was connected to N29, and $400 \mathrm{kWh}$ ESS was connected to N17. The difference between the results of cases 6 and 7 were described in detail in the following section.

Table 3. Size and connection bus of ESS units

\begin{tabular}{ccc} 
\# of Cases & Size $[\mathbf{k W h}]$ & Bus Number ESS connected \\
\hline Case 1 & None & None \\
\hline Case 2 & 600 & N17 \\
\hline Case 3 & 600 & N09 \\
\hline Case 4 & 600 & N29 \\
\hline Case 5 & 600 & N26 \\
\hline \multirow{2}{*}{ Case 6 6} & 300 & N29 \\
\cline { 2 - 3 } & 300 & N17 \\
\hline \multirow{2}{*}{ Case 7 } & 300 & N29 \\
\cline { 2 - 3 } & 400 & N17
\end{tabular}


According to the first LFA without ESS, the first overloaded line is L26, and the peak load for the first year is $920+j 950 \mathrm{kVA}$. ESS is placed between N26-N33. The second overloaded line is L7 without ESS, the peak load for the first year is $1075+j 510 \mathrm{kVA}$, and another ESS placement is between N07-N18. Considering ESS investment cost, expansion planning with $600 \mathrm{kWh}$ ESS makes penetration level $55 \%$ for cases 2 and 3, 65\% for cases 4 and 5, 60\% for case 6 , and $70 \%$ for case 7 . All cases' battery penetrations have been kept above $50 \%$, and size is referenced in $[20,21,30]$. Besides, the total losses of DES in each case are evaluated.

\section{Results and Discussion}

LFA is run for L years, and the results of LFA for the first case without ESS is given in Table 4. According to this result, there is no need to upgrade any line in the first six years. However, in the 7th year line, L02 is overloaded where the thermal limit of the line is reached. After four years of operation with the annual load growth factor, another line L03 needs upgrade while the loading of line L02 is reached $115 \%$ above the thermal limits. Third line needs upgrade is L26, which is overloaded in the 17th year, ten years after the first overloaded line. L27 needs upgrade after 1-year of L26, then L04 and L07 need upgrade one year later, then L05, L28, L29 need upgrade at the end of 20 years of operation. The distribution transformer is shown in Figure 3 also needs upgrade in each case, together with the first upgraded line. Hence, the distribution transformer is not shown in Table 4 but calculated.

Table 4. The years and the line numbers of upgraded lines

\begin{tabular}{lcccccccccccccc}
\hline Years $\rightarrow$ & $7^{\text {th }}$ & $\mathbf{8}^{\text {th }}$ & $\mathbf{9}^{\text {th }}$ & $\mathbf{1 0}^{\text {th }}$ & $\mathbf{1 1}$ & $\mathbf{1 2}^{\text {th }}$ & $\mathbf{1 3}^{\text {th }}$ & $\mathbf{1 4}^{\text {th }}$ & $\mathbf{1 5}^{\text {th }}$ & $\mathbf{1 6}^{\text {th }}$ & $\mathbf{1 7}^{\text {th }}$ & $\mathbf{1 8}^{\text {th }}$ & $\mathbf{1 9}^{\text {th }}$ & $\mathbf{2 0}^{\text {th }}$ \\
\hline Case 1 & L02 & - & - & - & L03 & - & - & - & - & - & L26 & L27 & L04, L07 & L05, L28, L29 \\
\hline Case 2 & - & - & - & - & L02 & - & - & - & L03 & - & L26 & L27 & - & L28 \\
\hline Case 3 & - & - & - & - & L02 & - & - & - & L03 & - & L26 & L27 & L28 & - \\
\hline Case 4 & - & - & - & - & L02 & - & - & - & L03 & - & - & - & - & L07 \\
\hline Case 5 & - & - & - & - & L02 & - & - & L03 & - & - & - & L27 & L28 & L07 \\
\hline Case 6 & - & - & - & - & L02 & - & - & - & L03 & - & - & - & - & L07, L26 \\
\hline Case 7 & - & - & - & - & - & L02 & - & - & L03 & - & - & - & - & \\
\hline
\end{tabular}

In case 2, the first line needs upgrade in the 11th year, and the second line needs upgrade in the 15th year. According to the results of case 2, the first two upgrading events are deferred four years later with ESS. In addition to this, the upgrading of lines L26, L27, and L28 are not deferred, while lines L04, L05, L07, and L29 do not need upgrade anymore. The total number of lines need upgrade in case 1 is 9 , but in case 2 is 5 . Four lines do not need upgrade anymore with ESS, but some upgrading events deferred four years. The results of case 2 are similar to case 3, while ESS size is still the same, but the placement of ESS is changed. In case 4, the first and second lines need upgrade in the 11th and 15th year, respectively. At the end of the 20 years, L07 needs upgrade. The total number of lines need upgrade is only 3, which are L02, L03, and L07. Again, the first two upgrading events are deferred four years with ESS in case 4. Upgrading events in case 5 is similar to case 3 , but the first two upgrading events are deferred for four years. For case 6 with decentralized ESS, upgrading of lines L02 and L03 are deferred similarly, but the number of lines is four that line L26 is added to the list of upgraded lines in case 4 . Another decentralized ESS case is case 7, in which only two lines L02 and L03, need upgrade at least a 4-year after. The numbers and length of lines to be upgraded in each case are given in Figure 4. For example, the number of lines to be upgraded in case 4 is three, while the total length of upgraded lines is near $9 \mathrm{~km}$. It is shown in Figure 4 that ESS placement prevents more lines from upgrade and leads to a decrease in LU investment. 


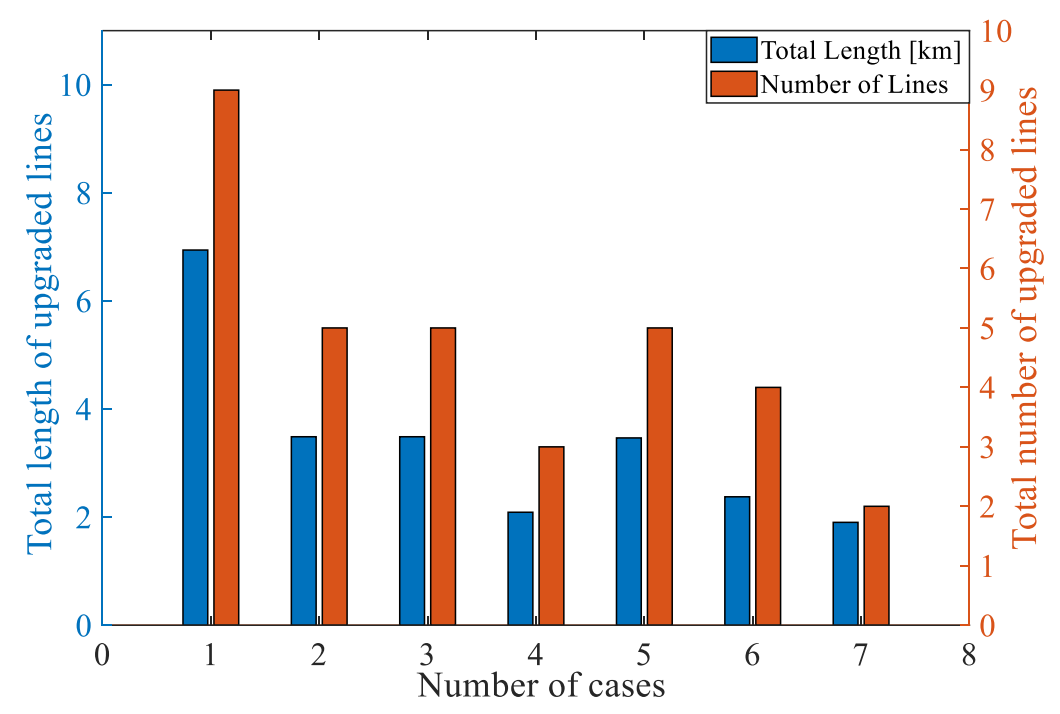

Figure 4. Number of lines to be upgraded and their length

In the overall results with ESS, the total length of upgraded lines is less than $3 \mathrm{~km}$, comparing the length in the base case 1 . The number of upgraded lines in case 4 is one in three, but the total length of upgraded lines is not decreased compared to case 1 since the lines in the two cases are not the same lengths.

The upgrading of distribution lines is illustrated in Figure 5-a without ESS and in Figure 5-b with ESS, respectively. In addition, the year when the line was upgraded has written above the line in Figure. 5. For example, the lines L04 was upgraded in the 19th year of operation if ESS was not used. With ESS, the line L04 does not need to be upgraded because no overloading exists in this line. Some lines need to be upgraded without ESS at the same time. For instance, L04 and L07 should be upgraded in the 19th year because overloading was started by the 19th. With ESS, there are only two lines, L02 and L03, need upgrade. Multiple upgrading needs occur in the late 20 years of operation. For instance, in the 7th, 11th, and 15th years, only one line was upgraded, but in the 19th and 20th years, two lines were upgraded in the same year. Namely, after 20 years without ESS support, totally 9 lines are upgraded. If ESS supports the distribution grid, only two lines are upgraded.

Moreover, the use of ESS not only diminished the number of upgraded lines but also deferred the upgrades to the future year. Distribution transformer and the line L02 have to be upgraded after inevitably upgraded at the 7th year of operation in all cases. However, this upgraded was deferred by four years to the 11th year, with ESS.

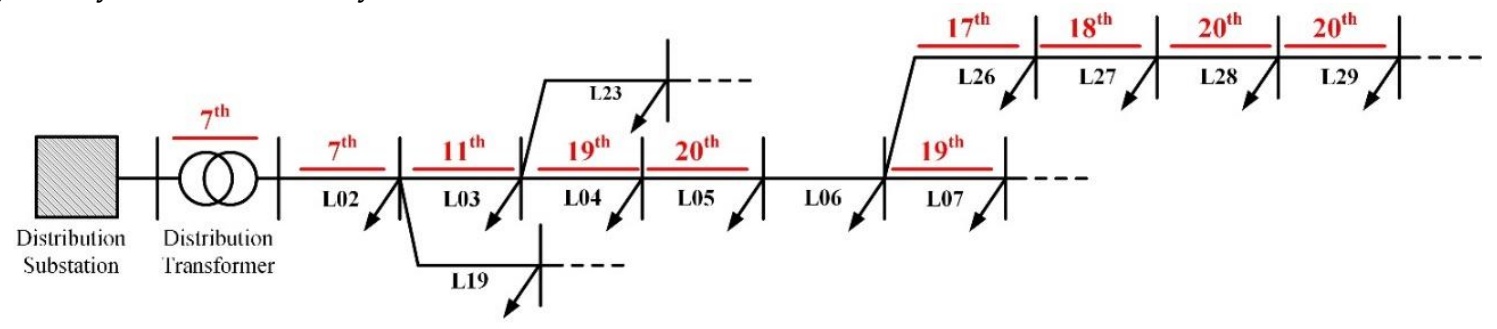

a)

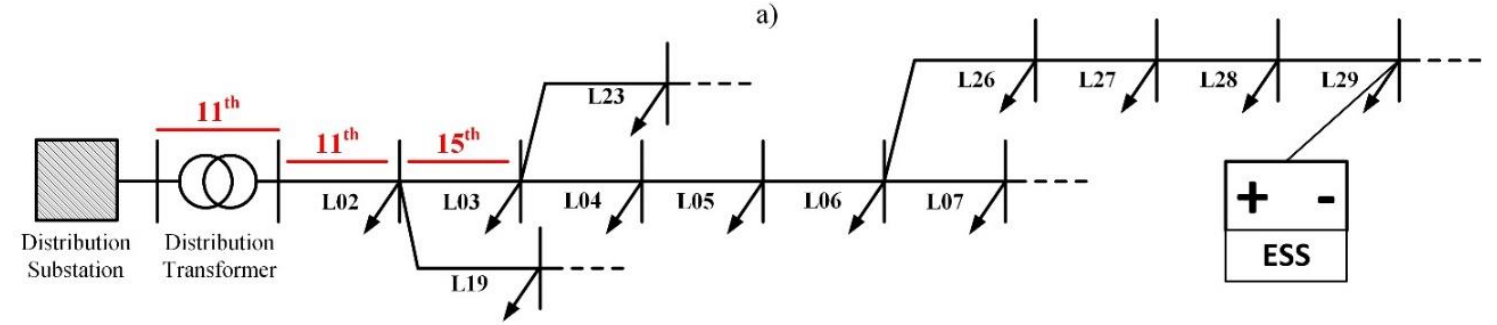

b) 
Figure 5. Lines need upgrade and when they need to be upgraded

a) Yearly upgraded lines need to be upgraded without ESS

b) Yearly upgraded lines need to be upgraded with ESS

ESS penetration and total losses for each case are given in Figure 6. The summation of power losses for each line is calculated by Eq. (2). It is assumed that the engagement of power losses on the loading of lines is a problem, especially during peak loads. During peak hours, the rate of losses on the line current is higher than off-peak hours. If the power losses are decreased, also overloading of the line can be postponed. Generally, outside of peak hours, losses are taken into account for only energy loss. Thus, the power losses during peak hours are only taken into account to determine the benefit of the proposed method easily. It can be stated from Figure 6 that power losses diminishing as the battery penetration is increased. The proposed method decreased the total power losses of lines in DES by $100 \mathrm{~kW}$ in case 6 .

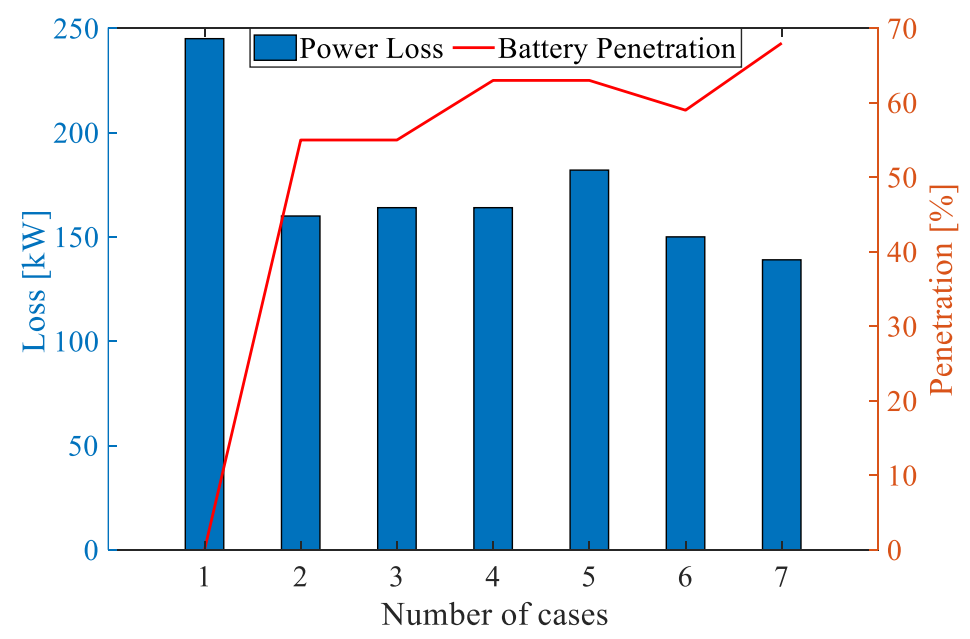

Figure 6. Power losses vs. battery penetration

The total LU cost of all upgraded lines is calculated for the base case through L year operation and given in Figure 7. In case 1, the full upgrade cost is over $\$ 7$ million without ESS. This cost includes the LU cost of 9 lines totally having $6.3 \mathrm{~km}$ length and one distribution transformer investments. In Figure 7 , it can be seen easily that the total investment cost in case 2 is decreased to below to $\$ 6$ million by expansion planning with ESS. The total upgrade cost in case 3 and case 5 are very similar to the cost in case 2. For case 4 , upgrade cost decreases by $\$ 1$ million due to the total length of upgraded lines decreased by one $\mathrm{km}$. Case 6 and 7 are the cheapest alternatives for the proposed method. Their total upgrade costs are very similar and slightly more than $\$ 2$ million. There is an obvious difference between cases 6-7 and 2-3-5 in total upgrade cost; hence total length and number of upgraded lines are less besides power losses are also reduced. It is noted that the costs seen in Figure 7 are related to lead-acid type ESS using expansion planning. 


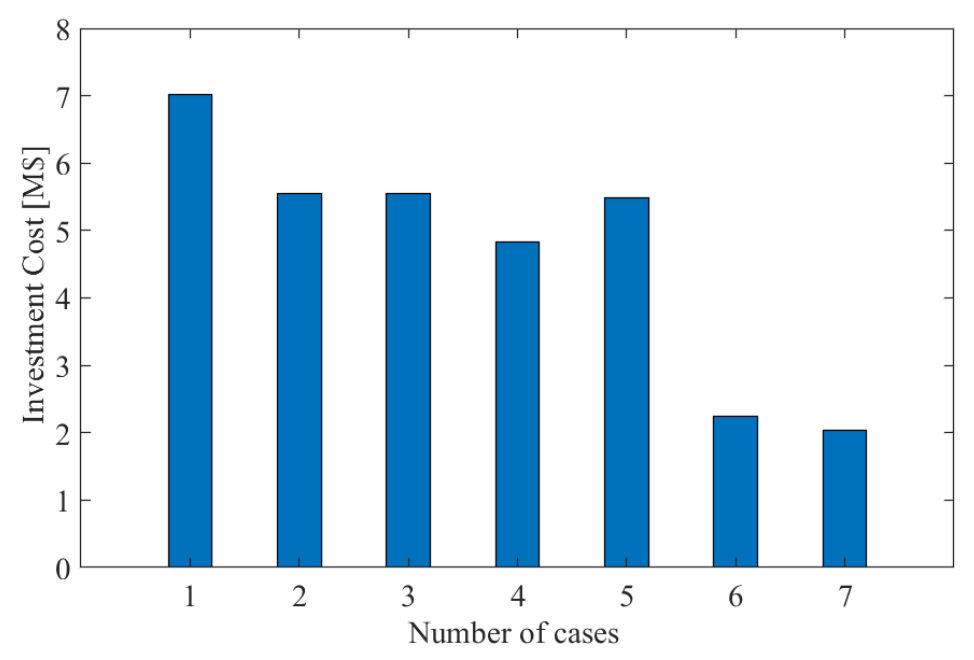

Figure 7. The change in the total upgrade cost using lead-acid type ESS

LU costs per km are taken from [43]. ESS costs can be found in reference [44]. For comparison of other types of ESS using to plan expansion of DES are given in Table 5. Total costs include an investment of different ESS types and DES upgrade costs. Total costs are changing according to ESS types. Although the highest cost related to vanadium redox and compressed air ESS because of the high investment cost, the total cost for VR and CA is less than without ESS. Total costs are decreased in any case in this study, thanks to ESS. Case 7 has the lowest cost due to the minimum number of upgraded lines with the minimum length. It is seen that expansion planning of DES with ESS can reduce the total cost by $\$ 3.91 \mathrm{M}$ to $\$ 4.66 \mathrm{M}$ according to ESS types. Additionally, lead-acid type ESS reduces mostly total cost because of lower installation costs. However, the cost of li-ion ESS is not much more than lead-acid, and it may decrease in the near future considering the availability of many second use EV batteries after 5-8 years use in EV.

Table 5. Total costs including investment of ESS and LU $[\$ M]$

\begin{tabular}{lcrrr}
\hline & Lead acid (LA) & Li-ion & Vanadium Redox (VR) & Compressed Air (CA) \\
\hline Case 1 & \multicolumn{3}{c}{7.02 (LU without ESS) } & 6.48 \\
\hline Case 2 & 5.83 & 5.89 & 6.12 & 6.48 \\
\hline Case 3 & 5.83 & 5.89 & 6.12 & 5.76 \\
\hline Case 4 & 5.11 & 5.17 & 5.40 & 6.41 \\
\hline Case 5 & 5.76 & 5.82 & 6.05 & 3.17 \\
\hline Case 6 & 2.52 & 2.58 & 2.81 & 3.11 \\
\hline Case 7 & 2.36 & 2.43 & 2.70 & \\
\hline
\end{tabular}

Figure 8 shows the results given in Table 5. Help to reader different colors used to illustrate the total cost of expansion planning of DES with ESS types. Total costs include LU and ESS investment and operational costs. 


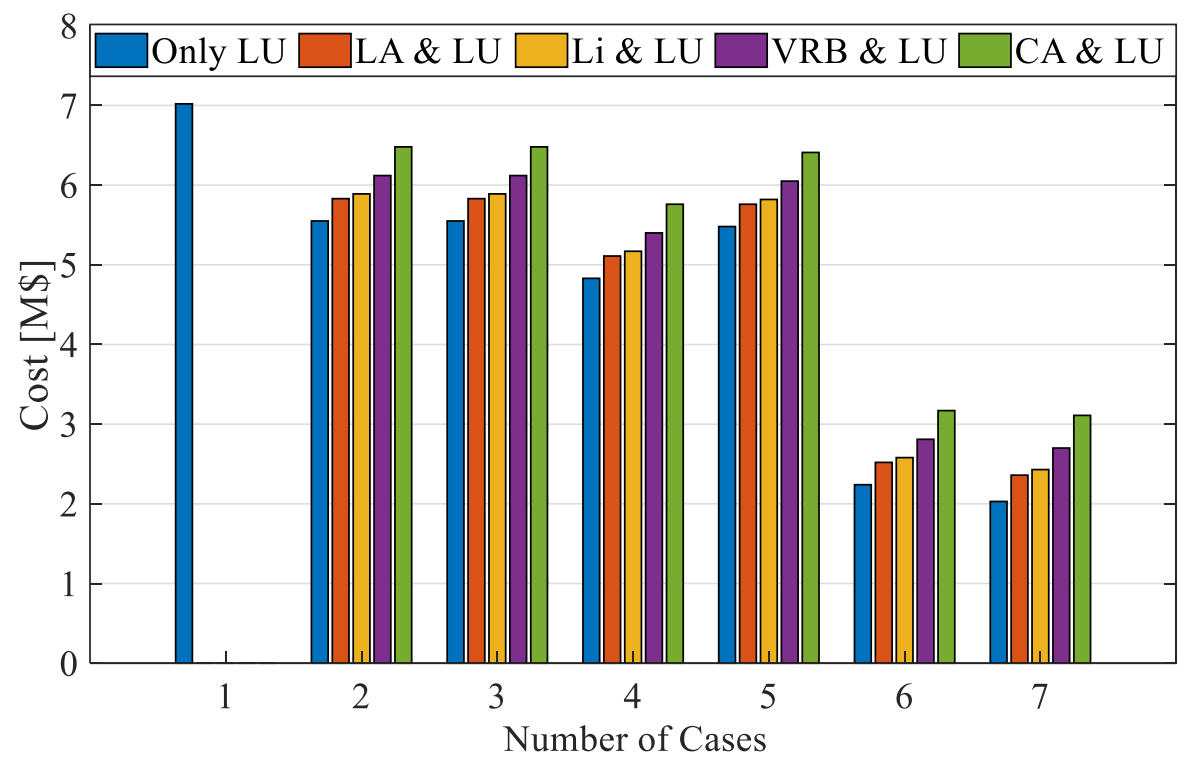

Figure 8. Total costs for different ESS types

Bus voltages drop due to line impedance increases as the current on the DES lines increases. To prevent bus voltages to violate the certain voltage limits, some precautions should take into consideration. Nevertheless, loads cannot be decreased; the stored energy in ESS can support DES loads especially the buses near the end of the line and ESS can help to compensate the bus voltages [45]. Expansion planning of DES with ESS can improve the bus voltages; especially in the peak hours, that voltage drop is higher via discharging of ESS to the demand of loads. The voltage changes are given for each case in Fig. 9.

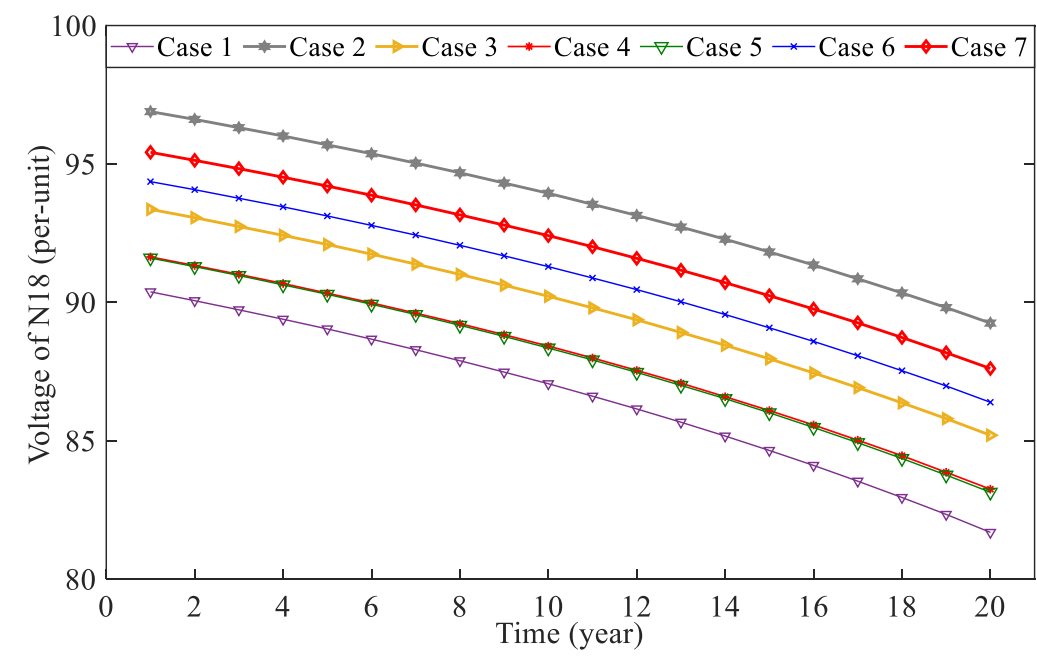

Figure 9. Comparison of the voltage of N18 throughout the study

Figure 9 shows the voltage drop of bus number N18, which is near the end of the line, during the L year operation with an annual load growth factor. Without ESS, the voltage of N18 is violating the limit. Namely, the voltage of N18 is below after the 6th year in case 1 . The voltage of N18 never goes below $80 \%$ after ESS used in cases 2, 6 and 7 until at the end of 20 years of operation.

The load growth factor used in the paper represents a highly developed region. Newly developed regions have higher load growth factor such as $7-10 \%$. Studies related to ESS investment are relied on the cost of ESS technologies continually improving. The cost projections of ESS in the 
literature are given in the short and long term. Short-term predictions include that the installation cost of ESS will be reduced by $21-67 \%$ in 2030 . Long term projections include more than $31 \%$ and not much than $80 \%$ for the year 2050 [46]. There is more reduction expectation of ESS price in the near future.

\section{Conclusions}

In this paper, the method for DES with ESS is proposed. With the proposed method, possible outages are prevented; LU cost is not only deferred, but also decreased. Proposed method is realized by the IEEE 33 bus DES model. DES is modeled with the help of PSS® Sincal software. LFA is run for 20 years with an annual load growth factor in DES for each case. Upgraded lines for each case are listed in detail with the year they need upgrade. Calculations are made with certain assumptions, and NPV is used to compare. As it can be seen that the number of upgraded lines is decreased, and the total length of upgraded lines are decreased.

As a result of different case studies, including centralized and decentralized ESS allocation, total cost, including LU cost and installation and operation costs of ESS are decreased without hampering the energy quality. Besides, power losses of DES are diminished expansion planning with ESS. In addition, the improvement of the bus voltage is examined. Voltages of buses in the DES model prevented to drop under $80 \%$ using ESS. Before ESS, voltage is under $75 \%$. According to the results, it is seen that the total upgrade cost has been shifted by $70 \%$, and total-operating costs of DES has been reduced to $34 \%$ for 20 years of operation. This result relies on the type of lead-acid ESS. For future studies on the integration of ESS in DES, possible reduction of specified prices of ESS due to developments of battery technologies could be taken into consideration. It is expected that a decrease in investment and operating costs of ESS can increase the techno-economic profitability of using ESS to a higher level. As a result, expansion planning in DES with ESS will increase.

Author Contributions: Conceptualization, S.M.T. and E.G.; methodology, S.M.T., O.E.; software, S.M.T.; validation, E.G., O.E. and.; formal analysis, S.M.T., O.E.; data curation, S:M.T.; writing-original draft preparation, S.M.T., O.E., U.C.; writing-review and editing, S.M.T., O.E. and U.C.; visualization, O.E.; supervision, E.G.; All authors have read and agreed to the published version of the manuscript.

Funding: This research received no external funding

Acknowledgments: No Acknowledgments

Conflicts of Interest: The authors declare no conflict of interest.

\section{References}

1. Venu, C.; Riffonneau, Y.; Bacha, S.; Baghzouz, Y. Battery storage system sizing in distribution feeders with distributed photovoltaic systems. 2009 IEEE Bucharest PowerTech Innov. Ideas Towar. Electr. Grid Futur. 2009, 1-5, doi:10.1109/PTC.2009.5282093.

2. Katsanevakis, M.; Stewart, R.A.; Junwei, L. A novel voltage stability and quality index demonstrated on a low voltage distribution network with multifunctional energy storage systems. Electr. Power Syst. Res. 2019, 171, 264-282, doi:10.1016/j.epsr.2019.01.043.

3. Bennett, C.J.; Stewart, R.A.; Lu, J.W. Development of a three-phase battery energy storage scheduling and operation system for low voltage distribution networks. Appl. Energy 2015, 146, doi:10.1016/j.apenergy.2015.02.012.

4. Tant, J.; Geth, F.; Six, D.; Tant, P.; Driesen, J. Multiobjective battery storage to improve PV integration in residential distribution grids. IEEE Trans. Sustain. Energy 2013, 4, 182-191, doi:10.1109/TSTE.2012.2211387.

5. Tercan, S.M.; Gökalp, E.; Kekezoğlu, B. Economic Analysis of Energy Storage Preventing Energy Outages in Distribution Grid in Turkey. In Proceedings of the 2018 6th International Conference on Control Engineering \& Information Technology (CEIT); IEEE, 2018; pp. 1-4.

6. Leou, R.C. An economic analysis model for the energy storage system applied to a distribution substation. Int. J. Electr. Power Energy Syst. 2012, 34, 132-137, doi:10.1016/j.ijepes.2011.09.016.

7. Chacra, F.A.; Bastard, P.; Fleury, G.; Clavreul, R. Impact of energy storage costs on economical performance in a distribution substation. IEEE Trans. Power Syst. 2005, 20, 684-691, doi:10.1109/TPWRS.2005.846091. 
8. Gil, H.A.; Joos, G. On the quantification of the network capacity deferral value of distributed generation. IEEE Trans. Power Syst. 2006, 21, 1592-1599, doi:10.1109/TPWRS.2006.881158.

9. Deeba, S.R.; Sharma, R.; Saha, T.K.; Chakraborty, D.; Thomas, A. Evaluation of technical and financial benefits of battery-based energy storage systems in distribution networks. IET Renew. Power Gener. 2016, 10, 1149-1160, doi:10.1049/iet-rpg.2015.0440.

10. Celli, G.; Loddo, M.; Pilo, F.; Abur, A. On-line network reconfiguration for loss reduction in distribution networks with distributed generation. IEE Conf. Publ. 2005, 4, 369-372, doi:10.1049/cp:20051270.

11. Celli, G.; Mocci, S.; Pilo, F.; Loddo, M. Optimal integration of energy storage in distribution networks. 2009 IEEE Bucharest PowerTech Innov. Ideas Towar. Electr. Grid Futur. 2009, 1-7, doi:10.1109/PTC.2009.5282268.

12. Zidan, A.; Shaaban, M.F.; El-Saadany, E.F. Long-term multi-objective distribution network planning by DG allocation and feeders' reconfiguration. Electr. Power Syst. Res. 2013, 105, 95-104, doi:10.1016/j.epsr.2013.07.016.

13. Meneses De Quevedo, P.; Contreras, J.; Rider, M.J.; Allahdadian, J. Contingency Assessment and Network Reconfiguration in Distribution Grids Including Wind Power and Energy Storage. IEEE Trans. Sustain. Energy 2015, 6, 1524-1533, doi:10.1109/TSTE.2015.2453368.

14. Ravadanegh, S.N.; Oskuee, M.R.J.; Karimi, M. Multi-objective planning model for simultaneous reconfiguration of power distribution network and allocation of renewable energy resources and capacitors with considering uncertainties. J. Cent. South Univ. 2017, 24, 1837-1849, doi:10.1007/s11771017-3592-8.

15. Fleischhacker, A.; Lettner, G.; Schwabeneder, D.; Auer, H. Portfolio optimization of energy communities to meet reductions in costs and emissions. Energy 2019, 173, 1092-1105, doi:10.1016/j.energy.2019.02.104.

16. Hung, D.Q.; Mithulananthan, N.; Lee, K.Y. Determining PV penetration for distribution systems with time-varying load models. IEEE Trans. Power Syst. 2014, 29, 3048-3057, doi:10.1109/TPWRS.2014.2314133.

17. Jayasekara, N.; Masoum, M.A.S.; Wolfs, P.J. Optimal operation of distributed energy storage systems to improve distribution network load and generation hosting capability. IEEE Trans. Sustain. Energy 2016, 7, 250-261, doi:10.1109/TSTE.2015.2487360.

18. Nick, M.; Cherkaoui, R.; Paolone, M. Optimal Planning of Distributed Energy Storage Systems in Active Distribution Networks Embedding Grid Reconfiguration. IEEE Trans. Power Syst. 2018, 33, doi:10.1109/TPWRS.2017.2734942.

19. Münderlein, J.; Steinhoff, M.; Zurmühlen, S.; Sauer, D.U. Analysis and evaluation of operations strategies based on a large scale $5 \mathrm{MW}$ and $5 \mathrm{MWh}$ battery storage system. J. Energy Storage 2019, 24, doi:10.1016/j.est.2019.100778.

20. Awad, A.S.A.; El-Fouly, T.H.M.; Salama, M.M.A. Optimal ESS allocation for load management application. IEEE Trans. Power Syst. 2015, 30, 327-336, doi:10.1109/TPWRS.2014.2326044.

21. Awad, A.S.A.; EL-Fouly, T.H.M.; Salama, M.M.A. Optimal ESS Allocation for Benefit Maximization in Distribution Networks. IEEE Trans. Smart Grid 2017, 8, 1668-1678, doi:10.1109/TSG.2015.2499264.

22. Kashem, M.A.; Ledwich, G. Energy requirement for distributed energy resources with battery energy storage for voltage support in three-phase distribution lines. Electr. Power Syst. Res. 2007, 77, 10-23, doi:10.1016/j.epsr.2006.01.008.

23. Saboori, H.; Hemmati, R.; Abbasi, V. Multistage distribution network expansion planning considering the emerging energy storage systems. Energy Convers. Manag. 2015, 105, 938-945, doi:10.1016/j.enconman.2015.08.055.

24. Purvins, A.; Sumner, M. Optimal management of stationary lithium-ion battery system in electricity distribution grids. J. Power Sources 2013, 242, 742-755, doi:10.1016/j.jpowsour.2013.05.097.

25. Eyer, J.M.J.; Corey, G.P. Energy Storage for the Electricity Grid: Benefits and Market Potential Assessment Guide A Study for the DOE Energy Storage Systems Program; 2010;

26. Chen, H.; Cong, T.N.; Yang, W.; Tan, C.; Li, Y.; Ding, Y. Progress in electrical energy storage system: A critical review. Prog. Nat. Sci. 2009, doi:10.1016/j.pnsc.2008.07.014.

27. Crampes, C.; Trochet, J.M. Economics of stationary electricity storage with various charge and discharge durations. J. Energy Storage 2019, 24, 100746, doi:10.1016/j.est.2019.04.020.

28. Akinyele, D.; Belikov, J.; Levron, Y. Battery storage technologies for electrical applications: Impact in stand-alone photovoltaic systems. Energies 2017, 10, 1-39, doi:10.3390/en10111760.

29. Ata, M.; Erenoglu, A.K.; Sengor, I.; Erdinc, O.; Tascikaraoglu, A.; Catalao, J.P.S. Optimal Operation of a Smart Multi-Energy Neighborhood. 2019, 1-6, doi:10.1109/ptc.2019.8810890.

30. Awad, A.S.A.; El-fouly, T.H.M.; Salama, M.M.A. Optimal ESS Allocation and Load Shedding for Improving Distribution System Reliability. IEEE Trans. Smart Grid 2014, 5, 2339-2349, 
doi:10.1109/TSG.2014.2316197.

31. PSS®SINCAL Modules for Electrical Network Planning Available online: https://new.siemens.com/global/en/products/energy/services/transmissiondistribution-smartgrid/consulting-and-planning/pss-software/pss-sincal/psssincal.html (accessed on Apr 29, 2020).

32. Baran, M.E.; Wu, F.F. Network reconfiguration in distribution systems for loss reduction and load balancing. IEEE Trans. Power Deliv. 1989, 4, 1401-1407, doi:https://doi.org/10.1109/61.25627.

33. Shen, X.; Shahidehpour, M.; Han, Y.; Zhu, S.; Zheng, J. Expansion Planning of Active Distribution Networks With Centralized and Distributed Energy Storage Systems. IEEE Trans. Sustain. Energy 2017, 8, 126-134, doi:10.1109/TSTE.2016.2586027.

34. Yang, Z.; Zhang, J.; Kintner-meyer, M.C.W.; Lu, X.; Choi, D.; Lemmon, J.P. Electrochemical Energy Storage for Green Grid. 2010.

35. Hoffman, M.; Kintner-Meyer, M.; Sadovsky, A.; DeSteese, J. Analysis Tools for Sizing and Placement of Energy Storage in Grid Applications: A Literature Review. U.S. Dep. Energy 2010, 1-56, doi:10.1115/ES2011-54834.

36. Sheibani, M.R.; Yousefi, G.R.; Latify, M.A.; Hacopian Dolatabadi, S. Energy storage system expansion planning in power systems: a review. IET Renew. Power Gener. 2018, 12, 1203-1221, doi:10.1049/ietrpg.2018.0089.

37. Lazzeroni, P.; Repetto, M. Optimal planning of battery systems for power losses reduction in distribution grids. Electr. Power Syst. Res. 2019, 167, 94-112, doi:10.1016/j.epsr.2018.10.027.

38. Ghosh, S.; Ghoshal, S.P.; Ghosh, S. Optimal sizing and placement of distributed generation in a network system. Int. J. Electr. Power Energy Syst. 2010, 32, 849-856, doi:10.1016/j.ijepes.2010.01.029.

39. Viswanathan, V. V.; Kintner-Meyer, M. Second use of transportation batteries: Maximizing the value of batteries for transportation and grid services. IEEE Trans. Veh. Technol. 2011, 60, 2963-2970, doi:10.1109/TVT.2011.2160378.

40. Cho, I.-H.; Lee, P.-Y.; Kim, J.-H. Analysis of the Effect of the Variable Charging Current Control Method on Cycle Life of Li-ion Batteries. Energies 2019, 12, 3023, doi:10.3390/en12153023.

41. Gong, Q.; Wang, Y.; Fang, J.; Qiao, H.; Liu, D. Optimal configuration of the energy storage system in ADN considering energy storage operation strategy and dynamic characteristic. IET Gener. Transm. Distrib. 2020, 14, 1005-1011, doi:10.1049/iet-gtd.2019.1274.

42. Jabbari Ghadi, M.; Azizivahed, A.; Rajabi, A.; Ghavidel, S.; Li, L.; Zhang, J.; Shafie-Khah, M.; Catalão, J.P.S. Day-Ahead Market Participation of an Active Distribution Network Equipped with Small-Scale CAES Systems. IEEE Trans. Smart Grid 2020, 11, 2966-2979, doi:10.1109/TSG.2020.2967937.

43. Wong, S.; Bhattacharya, K.; Fuller, J.D. Electric power distribution system design and planning in a deregulated environment. IET Gener. Transm., Distrib. 2009, 3, 1061-1078.

44. Lockhart, E.; Li, X.; Booth, S.S.; Olis, D.R.; Salasovich, J.A.; Elsworth, J.; Lisell, L. Comparative Study of Techno-Economics of Lithium-Ion and Lead-Acid Batteries in Micro-Grids in Sub-Saharan Africa. Natl. Renew. Energy Lab. 2019, 36, doi:10.2172/1526204.

45. Zeraati, M.; Hamedani Golshan, M.E.; Guerrero, J.M. Distributed Control of Battery Energy Storage Systems for Voltage Regulation in Distribution Networks with High PV Penetration. IEEE Trans. Smart Grid 2018, 9, 3582-3593, doi:10.1109/TSG.2016.2636217.

46. Cole, W.; Frazier, A.W. Cost Projections for Utility- Scale Battery Storage Cost Projections for UtilityScale Battery Storage. Natl. Renew. Energy Lab. 2019, NREL/TP-6A20-73222. 